\section{"DEIXO ELA NO CANTO E VOU TOCAR MINHA VIDA": SIGNIFICADOS DE VIVER COM HIV PARA HOMENS COM ADESÃO IRREGULAR À TERAPIA ANTIRRETROVIRAL}

\section{'I leave it alone and then I go on with my life': meanings of living with HIV for men in irregular adherence to antiretroviral therapy}

\author{
"La dejo y voy a seguir con mi vida": signifcados de vivir \\ con VIH en hombres con adhesión irregular a la terapia \\ antiretroviral
}

Artigo Original

\section{RESUMO}

Objetivo: Descrever e analisar os significados de viver com o vírus da imunodeficiência humana (HIV) para homens com adesão irregular à terapia antirretroviral (TARV). Métodos: Pesquisa qualitativa, realizada em um ambulatório de um hospital universitário no interior de Minas Gerais, com participação de 10 homens. Os dados foram coletados entre maio e setembro de 2011 através de entrevista semiestruturada e submetidos à análise de conteúdo, resultando nas categorias temáticas "Descobrindo a contaminação pelo HIV" e "(Com)Vivendo com o HIV". Resultados: Os significados de viver com HIV são marcados pela coexistência de algumas concepções equivocadas sobre HIV/AIDS, consolidadas no início da epidemia, com novas percepções, provenientes dos ganhos advindos da utilização da TARV, associadas à valorização de características que trazem uma percepção de invulnerabilidade pelo homem. Esses aspectos podem ser compreendidos como fatores que se refletem diretamente na forma como os sujeitos aderem ou não à TARV. Além disso, destacam-se também as limitações impostas pelas condições concretas de vida dos sujeitos, principalmente no que se refere ao âmbito socioeconômico e cultural. Conclusão: O processo de viver com HIV caracteriza-se pela complexidade, o que suscita o planejamento de ações de saúde, numa perspectiva de gênero que atenda às especificidades do universo masculino.

Descritores: HIV; Síndrome de Imunodeficiência Adquirida; Saúde do Homem; Pesquisa Qualitativa.

\section{ABSTRACT}

Objective: To describe and analyze the meanings of living with the Human Immunodeficiency Virus (HIV) for men with irregular adherence to Antiretroviral Therapy (ART). Methods: Qualitative research conducted at an ambulatory of a school hospital in Minas Gerais, Brazil, with 10 men. Data was collected from May to September 2011 through semi-structured interview and submitted to content analysis, resulting in the categories "Discovering the HIV infection" and "Living with HIV". Results: The meanings of living with HIV are distinguished by the coexistence of some misconceptions about HIV/AIDS, consolidated in the epidemic onset, with new perceptions, derived from the gains resulting from use of ART, associated to the valuation of features that bring a sense of non-vulnerability to the man. These aspects can be understood as factors that are directly reflected in the way that the participant men adhere (or not) to ART. Moreover, the limitations imposed by the real conditions of the individuals' life are highlighted, especially concerning the socioeconomic and cultural context. Conclusion: The process of living with HIV is characterized by complexity, which indicates the planning of health actions from a gender perspective to address the specificities of the masculine universe.

Descriptors: HIV; Acquired Immunodeficiency Syndrome; Men's Health; Qualitative Research.

\author{
Daniela Tavares Gontijo(1) \\ Ana Paula Guimarães Cunha ${ }^{(2)}$ \\ Maria Regina Pontes Luz \\ Riccioppo $^{(2)}$ \\ Rodrigo Juliano Molina ${ }^{(2)}$ \\ Marcelo Medeiros ${ }^{(3)}$
}

1) Universidade Federal de Pernambuco UFPE - Recife (PE) - Brasil

2) Universidade Federal do Triângulo Mineiro - UFTM - Uberaba (MG) - Brasil

3) Universidade Federal de Goiás - UFG Goiânia (GO) - Brasil
Recebido em: 07/12/2012 Revisado em: 07/06/2013 Aceito em: 03/09/2013 


\section{RESUMEN}

Objetivo: Describir y analizar los significados de vivir con el virus de inmunodeficiencia humana (VIH) en hombres con adhesión irregular a la terapia antiretroviral (TARV). Métodos: Investigación cualitativa realizada en un ambulatorio de un hospital universitario en un pueblo de Minas Gerais con participación de 10 hombres. Los datos fueron recogidos entre mayo y septiembre de 2011 a través de entrevista semi-estructurada y sometidos al análisis de contenido resultando en las categorías temáticas "Descubriendo la contaminación por el VIH" y "(Con) Viviendo con el VIH”. Resultados: Los significados de vivir con el VIH son marcados por la coexistencia de algunas concepciones equivocadas sobre VIH/SIDA consolidadas en el inicio de la epidemia con nuevas percepciones provenientes de las ganancias advenidas de la utilización de la TARV asociadas a la valorización de características que traen una percepción de invulnerabilidad del hombre. Eses aspectos pueden ser comprendidos como factores que se reflejan directamente en la forma como los sujetos adhieren o no a la TARV. Además, se destaca también las limitaciones impuestas por las condiciones concretas de vida de los sujetos, principalmente en lo que se refiere al ámbito socioeconómico y cultural. Conclusión: El proceso de vivir con VIH se caracteriza por la complejidad, lo que suscita el planeamiento de acciones en salud en una perspectiva de género que atienda a las especificidades del universo masculino.

Descriptores: VIH; Síndrome de Inmunodeficiencia Adquirida; Salud del Hombre; Investigación Cualitativa.

\section{INTRODUÇÃO}

A potencialização da busca e adesão dos homens aos serviços de saúde, especialmente daqueles que vivem com o Vírus da Imunodeficiência Humana (HIV), caracterizase como um desafio cotidiano nos serviços de saúde. Considerando as altas taxas de mortalidade dos homens quando comparadas às das mulheres ${ }^{(1-5)}$, no Brasil, um dos focos de análise no cenário acadêmico tem sido as possíveis relações entre as construções socioculturais em torno da masculinidade e a vulnerabilidade dos homens a algumas doenças e estilos de vida que afetam a saúde ${ }^{(2,3,5,6)}$.

A masculinidade ou as masculinidades se constituem como modelos que servem para formar a identidade do ser homem, que influenciam as atitudes, os comportamentos e as emoções a serem seguidas em uma determinada cultura ${ }^{(2,4)}$. Nesse sentido, essas construções socioculturais podem se constituir como fatores que ampliam ou minimizam a vulnerabilidade do homem em relação à sua saúde, uma vez que podem afastá-lo ou aproximá-lo do cuidado de $\mathrm{si}^{(6)}$.

Estudos $^{(2-4)}$ têm sido realizados para compreender as influências da associação entre a valorização de determinados atributos (como percepção de invulnerabilidade, força, ímpeto sexual e relações hierárquicas e opressoras de gênero) e a saúde na construção da identidade cultural do homem. Essas pesquisas apontam que a valorização exacerbada dessas características na construção da masculinidade pode atuar como um fator que aumenta a vulnerabilidade dos homens, pois limita as possibilidades de eles buscarem os serviços de saúde e adotarem medidas preventivas e de autocuidado.

Considerando esses aspectos e outras demandas quanto à saúde do homem, o Ministério da Saúde criou, em 2008, a Política Nacional de Atenção Integral à Saúde do Homem $(\mathrm{PNSH})^{(7)}$. Entre as diretrizes preconizadas na PNSH, destaca-se a ênfase na implementação de medidas preventivas em relação a diversas doenças, inclusive as sexualmente transmissíveis, como a Síndrome da Imunodeficiência Adquirida Humana (AIDS) ${ }^{(7)}$.

Estima-se que, atualmente, haja 33,2 milhões de pessoas vivendo com HIV em todo o mundo ${ }^{(5)}$. A discussão da epidemia do HIV e da efetividade das medidas preventivas tem sido articulada em torno do conceito da vulnerabilidade(4). A adoção da vulnerabilidade enquanto marco referencial possibilita a compreensão de como dimensões individuais, sociais e programáticas integram e resultam em maior ou menor susceptibilidade à infecção pelo HIV e à morte pela $\operatorname{AIDS}^{(8)}$.

Apesar dos avanços relacionados à descoberta e ao acesso à Terapia Antirretroviral (TARV), que contribui para a melhora da qualidade de vida dos infectados, estudos constatam a baixa adesão ao tratamento ${ }^{(9-12)}$.

Entende-se que a adesão é uma atividade conjunta, na qual o usuário do serviço de saúde não só obedece às orientações médicas, mas entende, concorda e segue a prescrição estabelecida pelo seu médico ${ }^{(13)}$. Segundo a Organização Mundial de Saúde, "as taxas de ingestão devem ser de no mínimo $95 \%$ do total de medicamentos prescritos para a obtenção da efetividade terapêutica"(14,p.132). A não adesão pode possibilitar a origem de micro-organismos resistentes, com prejuízo para tratamentos posteriores, assim como resultar no agravamento da doença, muitas vezes de forma irreversível ${ }^{(15-17)}$. Em um estudo de revisão bibliográfica, identificou-se que o nível de não adesão ao medicamento antirretroviral variou de $5 \%$ a $67 \%{ }^{(16)}$.

A adesão ou a não adesão é um fenômeno complexo, resultante da interação de diferentes fatores ${ }^{(9)}$. Entre os fatores que dificultam o processo terapêutico, destacamse: o grande número de comprimidos, as reações adversas (intolerância), a necessidade de períodos de jejum, a incompatibilidade com as drogas, a dificuldade na compreensão das metas da terapia, o medo de que outras pessoas descubram a contaminação pelo HIV, a baixa escolaridade, a baixa renda e o uso atual e abusivo de álcool ${ }^{(10,11,17)}$. 
Por outro lado são identificados como fatores que podem facilitar a adesão o conhecimento e compreensão sobre a enfermidade e o tratamento; o vínculo com os profissionais, a equipe e o serviço de saúde; o apoio social e o conhecimento dos direitos fundamentais da pessoa portadora do vírus $\mathrm{HIV}^{(15,18)}$.

Especificamente em relação aos homens vivendo com HIV, estudos têm apontado a carga horária de trabalho incompatível com os horários de funcionamento dos serviços de saúde, os efeitos adversos dos medicamentos e a influência do modelo de masculinidade hegemônico como fatores que contribuem para a não adesão ao tratamento ${ }^{(10-12,17,19)}$.

Com base no apontado, o objetivo do presente estudo é descrever e analisar os significados de viver com o Vírus da Imunodeficiência Humana (HIV) para homens com adesão irregular à Terapia Antirretroviral (TARV).

\section{MÉTODOS}

Pesquisa com abordagem qualitativa ${ }^{(20,21)}$, realizada no ambulatório de um hospital universitário localizado em uma cidade na região do Triângulo Mineiro (Minas Gerais), referência no acompanhamento de pacientes contaminados pelo HIV. Nesse ambulatório, detectaram-se casos de adesão irregular à TARV entre homens, o que suscitou o questionamento sobre quais os significados atribuídos por estes ao viver com o HIV e de como eles podem relacionar esse comportamento em relação ao tratamento.

Foram convidados a participar do estudo homens acima de 18 anos, diagnosticados com HIV, em acompanhamento médico, com indicação de TARV e adesão irregular a esta. A adesão irregular, neste trabalho, foi caracterizada como situações de faltas sem justificativa a duas consultas consecutivas e/ou abandono da TARV por um período igual ou superior a 20 dias. Definiu-se o número de participantes, representado por 10 sujeitos, pelo critério de saturação teórica para pesquisas qualitativas ${ }^{(21)}$.

Os dados coletados através de entrevistas semiestruturadas, individuais e realizadas em uma sala privativa ou em visitas domiciliares, no período de maio a setembro de 2011, foram gravados em meio digital e posteriormente transcritos.

As entrevistas direcionaram-se por um roteiro com questões referentes às características gerais dos sujeitos, ao processo de descoberta da contaminação e do viver com HIV. Os sujeitos também foram solicitados a falar sobre como é e o que acham do tratamento que realizam e das dificuldades encontradas.

Analisaram-se os dados por meio da análise de conteúdo temática para pesquisas qualitativas ${ }^{(22)}$, respeitando os seguintes procedimentos: leitura exaustiva do material coletado, identificação e agrupamento de manifestações semelhantes por meio de categorias, e posterior discussão. Esse processo resultou em duas categorias temáticas, que articulam dados empíricos (objetivos do estudo e referencial teórico), denominadas "Descobrindo a contaminação pelo HIV" e "(Com)Vivendo com o HIV"

Este estudo recebeu aprovação do Comitê de Ética em Pesquisa com Seres Humanos da Universidade Federal do Triângulo Mineiro (Parecer 1837), sendo as entrevistas realizadas após a leitura e assinatura do Termo de Consentimento Livre e Esclarecido pelos sujeitos. Os participantes são identificados como entrevistados (E1, E2 e assim sucessivamente), a fim de garantir o anonimato.

\section{RESULTADOS E DISCUSSÃO}

Participaram da pesquisa 10 homens, com idade média de 33 a 66 anos e tempo de infecção pelo HIV de 4 a 20 anos. O tempo médio de descoberta do diagnóstico, de acordo com o relatado pelos sujeitos, foi de 10,77 anos, e todos tinham histórico de abandono da TARV por mais de 20 dias. No que se refere ao estado civil, eram 4 casados, 5 solteiros e 1 divorciado, e todos só referiram práticas sexuais com mulheres. Um estudo ${ }^{(14)}$ realizado na região Sul do Brasil avaliou a adesão aos antirretrovirais junto a 67 pacientes e encontrou idades entre 24 e 65 anos (média de 41,03), com média de tempo do diagnóstico de 5,8 anos.

\section{Descobrindo a contaminação pelo HIV}

A primeira categoria temática, denominada "Descobrindo a contaminação pelo HIV", além da discussão sobre a reação dos sujeitos participantes ao diagnóstico, aborda aspectos relacionados à adoção de medidas preventivas pelos homens.

A maior parte dos participantes se contaminou por via sexual, mas, para dois sujeitos, isso se deu por compartilhamento de seringas no uso de drogas. Entre os sujeitos infectados por via sexual, destacaram-se dois aspectos que se relacionam à percepção de si enquanto não vulnerável ao HIV antes da contaminação: o não uso de métodos preventivos em relações consideradas estáveis, e a não suspeita de que pessoas com aparência saudável poderiam estar contaminadas, conforme as falas a seguir:

"Eu morava com uma mulher que tinha (AIDS) e nós não sabiamos. A gente separou. No decorrer do tempo, ela teve uma pneumonia e foi internada aqui, ai que descobriu e me comunicou." (E3)

“(...) Era casado, né? (...) Principalmente... Inclusive nem suspeitava, porque era uma pessoa que não dava pra 
imaginar (...). Na época, não tinha muito conhecimento (...), né? (...) Porque sempre quando eles falavam, falavam que a pessoa estava deformada, com gripe, emagrecendo, né? (...) Então a gente (...) olhava a pessoa pelo corpo, assim, e falava 'não... não tem nada, né? (...) Não é possivel'." (E5)

A não associação direta entre a possibilidade de infecção pelo HIV e pessoas com aparência saudável, explicita a permanência de concepções que associam a AIDS e a contaminação pelo HIV a "grupos de risco" e ao estereótipo físico da pessoa doente, presentes no início da epidemia, na década de 1980, anterior ao advento e avanço da TARV ${ }^{(23,24)}$, e atualmente não sustentadas pelos serviços de saúde.

De forma concomitante a essas concepções, a não adoção de métodos preventivos em relação às Doenças Sexualmente Transmissíveis (DST) nos relacionamentos considerados estáveis pelos homens amplifica a vulnerabilidade destes e suscita a discussão acerca de como os processos que permeiam as construções socioculturais sobre gênero influenciam comportamentos direcionados ao autocuidado.

A expressão 'gênero' "refere-se a papéis socialmente construídos e a definições e expectativas - consideradas apropriadas em uma sociedade - para o ser homem e o ser mulher"(25). Considerando-se que as características dos modelos culturais de gênero constituem e validam socialmente o que é compreendido como "ser homem" em determinado contexto (histórico, econômico e temporal), elas não podem ser relegadas na análise realizada pelos profissionais da saúde relativas à contaminação/prevenção da AIDS.

Nas falas dos sujeitos, observa-se a associação entre relacionamentos estáveis e o não uso do preservativo. Esse aspecto foi discutido em uma pesquisa que analisou a produção científica sobre homens e prevenção da AIDS no período de 1997 a $2009^{(5)}$. Nela, os autores apontam que algumas das dificuldades para o uso de preservativos pelos homens podem se relacionar à percepção de intimidade entre os parceiros e à constatação de que essa prática vai de encontro, simbolicamente, a atributos que constituem aspectos das masculinidades hegemonicamente valorizadas em nossa cultura. Nesse sentido, entre outros aspectos, o uso do preservativo em relacionamentos estáveis poderia levar ao questionamento da imagem do "bom homem e marido fiel" que não tem medo de lidar com o risco ${ }^{(5)}$.

No entanto, é importante ressaltar que a adoção de medidas preventivas no âmbito da sexualidade, em especial no tocante à AIDS, caracteriza-se como um fenômeno complexo e dinâmico, constituído tanto por concepções culturalmente valorizadas (ou não) quanto por processos de subjetivação que se constroem em meio às (im) possibilidades concretas de vida. Nesse sentido, enfatizase a necessidade de escuta dos homens e a problematização de suas vivências e especificidades pelos profissionais de saúde, a fim de sistematizar ações realmente efetivas direcionadas para a promoção de saúde sexual ${ }^{(5)}$.

O momento do diagnóstico foi marcado pelo choque e pela tristeza para alguns entrevistados:

\section{“(...) Na época, foi um baque. Durante uns seis meses eu vivi assim..." (E2)}

Outros relataram que a noticia da contaminação pelo HIV foi recebida com certa naturalidade:

“(...) Olha, eu não fiquei triste nem alegre, você entendeu? Uma pessoa normal... saí andando... vou cuidar, né?" (E3)

A reação ao diagnóstico de uma determinada doença está intrinsecamente relacionada à representação subjetiva que o sujeito tem acerca dela. Assim, compreende-se que a reação de certa "naturalidade" ao receber o diagnóstico de HIV, relatada por alguns dos homens entrevistados no presente estudo, pode apontar uma mudança na representação da AIDS, a qual estaria não mais associada diretamente à condição de doença fatal, o que também foi percebido em outros estudos ${ }^{(5,26)}$.

Outro entrevistado destaca a substituição da percepção inicial da contaminação pelo HIV como uma condição fatal pela significação dela como uma condição crônica:

“(...) Eu pensei que ia morrer rapidinho, que não tinha mais solução, mas eu vi que não era assim, né? (...)” (E7)

Essapercepçãoé corroborada pelos outros entrevistados, que, apesar de relatarem diversas dificuldades em conviver com o vírus HIV, apontam a necessidade de continuar o processo de vida, apesar da doença:

“(...) Eu (risos) deixo ela no canto e vou tocar minha
vida, e vou indo...” (E7)

É importante destacar que a representação da AIDS como condição crônica, também problematizada em outros estudos $^{(5,26)}$, associada a não percepção da possibilidade de contaminação nas relações sexuais com pessoas de aparência saudável, pode se caracterizar como um fator que amplifica a vulnerabilidade ao HIV, tanto em homens quanto em mulheres. 
Um aspecto que chamou a atenção no conjunto das falas foi a relação estabelecida por outros entrevistados entre o diagnóstico e a época da vida na qual foi realizado, pois, na adolescência, ele representa um impacto maior do que quando obtido na vida adulta, em virtude de uma maior expectativa de vida, de acordo com as falas a seguir:

"Ah, foi dificil, porque eu estava na adolescência, né? (...) Foi muito dificil [...] para (ter) informações, tratamentos, para ter uma vida longa..." (E8)

“(...) Eu não liguei, não, porque [...] eu estava com cinquenta e tantos [anos]; já estava no fim mesmo. Se fosse um adolescente de 18 anos, tudo bem, tem muita vida. E eu não tinha, aí não liguei, não." (E4)

Essa percepção pode se relacionar com a representação da contaminação pelo HIV/AIDS como uma doença crônica, conforme já discutido, e vai ao encontro dos estudos que têm apontado o aumento da incidência de contaminação entre sujeitos mais velhos, inclusive entre idosos ${ }^{(23)}$.

\section{(Com)Vivendo com o HIV}

Os conteúdos referentes ao processo de viver após o diagnóstico da contaminação pelo HIV são discutidos na categoria temática "(Com)Vivendo com o HIV". Os dados desta categoria refletem como fatores individuais, sociais e programáticos influenciam o significado de viver com o HIV e configuram as diferentes situações de vulnerabilidade que podem agravar a situação de saúde dos participantes, principalmente no que se refere às (im)possibilidades desses homens de aderirem, de forma efetiva, à TARV.

Quando solicitados a falarem sobre as mudanças decorrentes da contaminação pelo HIV, os sujeitos apontaram mudanças físicas ocorridas em função de doenças oportunistas, alterações do sono e humor, e, principalmente, aparecimento de quadros depressivos:

\section{“(...) Eu tive vários tumorzinhos no cérebro que a doença causou.”(E6) \\ “(...) Ela [a doença] mexe com o psicológico. Foi difícil.” (E8)}

Além disso, os entrevistados relataram mudanças na rotina cotidiana, em virtude da necessidade de medidas preventivas direcionadas a não contaminação por outras doenças, como pode ser visto na fala a seguir:

“(...) Eu não bebo café, nada em bar, porque tenho medo de tomar no copo dos outros... Por causa da hepatite. Eu tenho HIV, pegar hepatite seria fatal..." (E2)
O diagnóstico de HIV impulsiona a pessoa a refletir sobre seus padrões de comportamento, suas crenças e valores. A reflexão pode desencadear mudanças no comportamento individual $\mathrm{e}$, assim, minimizar a vulnerabilidade ao adoecimento ${ }^{(15)}$. Assim como observado durante as entrevistas, outros estudos mostram que manter alimentação e hábitos saudáveis, e diminuir a exposição a outras doenças infectocontagiosas, uma vez que estas repercutem diretamente no tratamento/cuidado, são estratégias adotadas por alguns portadores ${ }^{(26,27)}$.

Ainda no que se refere ao impacto do HIV na trajetória de vida, destacaram-se as mudanças, de caráter restritivo, no estabelecimento e manutenção de relações afetivas e sexuais, uma vez que os homens passaram a ter medo de contaminar outras pessoas, como mencionado a seguir:

\begin{abstract}
“(...) Eu tive vários relacionamentos, namoradas, né? Simplesmente tive que virar as costas para essas pessoas, porque é o seguinte: estava começando a ficar perigoso, a gente estava começando a se gostar verdadeiramente... Quando chegava na hora de deitar junto ou de eu ir morar junto com a pessoa, eu tive que virar as costas pra essa pessoa e ir embora..." (E3)
\end{abstract}

As mudanças relacionadas à vida sexual e reprodutiva dos portadores de HIV foram analisadas por pesquisadores, que apontam o pouco direcionamento de informação nos serviços especializados para portadores de HIV/AIDS sobre a vida afetiva e sexual destes ${ }^{(23)}$.

A política pública existente sobre direitos sexuais e reprodutivos, teoricamente, inclui todos os indivíduos, inclusive os portadores de infecções e doenças crônicas ${ }^{(28)}$. No entanto, no que diz respeito ao exercício da sexualidade de pessoas com HIV, há preconceito e estigmatização, decorrentes, sobretudo, do constructo de noções de "grupo de risco" e "transmissão", veiculadas quando da descoberta da $\operatorname{AIDS}^{(28)}$.

Nesse sentido, acredita-se que o planejamento de ações de saúde sexual e reprodutiva para esse grupo não pode ser subsidiado apenas pelas estatísticas sobre as probabilidades de contaminação pelo HIV, pois devem incluir a compreensão dos processos subjetivos que envolvem a vivência da sexualidade nos contextos reais de vida dos sujeitos.

Outro aspecto destacado pelos entrevistados no presente estudo se refere ao impacto do preconceito, conforme destacado no trecho a seguir. Estudos mostram que o preconceito assume lugar de destaque nas preocupações dos infectados, favorecendo a baixa adesão ao tratamento ${ }^{(13,17,27,29)}$.

“(...) E o preconceito não acabou, né? (...) Sem querer, você troca de copo; sem querer, você troca de prato; sem 
querer, troca de garfo; sem querer, não te emprestam uma blusa; sem querer, não querem nada seu também. Então, isso dai é chato; é uma coisa que machuca, sabe?" (E3)

Os entrevistados relataram comportamentos de omissão da doença em seus grupos sociais, devido ao medo de discriminação por parte dos amigos e familiares ou de demissão no trabalho.

“(...) Não, se a gente contar, eles mandam a gente embora..." (E7)

“(...) Ah, ela [mãe] não ia ter uma reação boa, porque é esse pessoal antigo, né? (...) Sistema antigo, então eles não aceitam, né? (...) Tem discriminação.” (E5)

Por outro lado, o suporte social representado pelo cuidado recebido de companheiras e/ou familiares é destacado pelos sujeitos como o principal alicerce no enfrentamento do processo de viver com o HIV.

“(...) É essencial. No tratamento... a familia toda se puder acompanhar é melhor, é mais fácil. Fica mais fácil pra gente... porque o soropositivo precisa de carinho também, e familia é algo principal..." (E8)

Compreende-se que o medo do preconceito e do isolamento faz com que os sujeitos soropositivos evitem revelar o diagnóstico até mesmo para familiares e companheiros, limitando a convivência e as fontes de suporte social ${ }^{(30)}$.

Ações de ampliação da rede social de suporte às pessoas que convivem com o HIV são vitais, mas perpassam a estruturação de serviços de atendimento a esse grupo que possibilitem a constituição de espaços de trocas e aprendizagem entre os sujeitos e abordem as dimensões sociais e emocionais que demarcam o viver com o HIV. A constituição desses espaços deve ser concomitante ao estabelecimento de intervenções direcionadas para a sociedade em geral, contribuindo para a desconstrução de concepções histórica e culturalmente construídas que sustentam a estigmatização social em torno da AIDS/HIV.

Essas estratégias se justificam pelo fato de que o apoio e a disponibilidade social aumentam a sobrevida dos enfermos, amenizando o sofrimento, contribuindo para o sucesso do tratamento, diminuindo os efeitos patogênicos do estresse no organismo e aumentando a capacidade das pessoas em lidar com situações difíceis e reorganizar as suas vidas ${ }^{(13,17,30,31)}$.

No presente trabalho, destacaram-se os fatores que se relacionam e influenciam na adesão irregular dos homens participantes da TARV. De forma consensual, os entrevistados caracterizaram o tratamento para o HIV como sinônimo de frequência às consultas médicas:
"Ah... pra mim, é normal. Venho na consulta, pego a medicação, tomo em casa...” (E8)

Os entrevistados atribuíram ao tratamento grande importância, inclusive associando o uso de medicamentos à possibilidade de continuar a viver:

“(...) Não posso ficar brincando com a vida, não, certo?” (E3)

No entanto, é importante destacar que, contraditoriamente à valorização racional do tratamento, todos os participantes do presente estudo se caracterizam por atitudes de adesão irregular ao uso da TARV durante alguns períodos. Essa concepção unânime que associa o tratamento para o HIV às consultas médicas e ao uso da TARV, corroborada pela ausência de menções a outras abordagens de cuidado disponíveis na prática de outros profissionais, como psicólogo, enfermeiro, terapeuta ocupacional, nutricionista, assistente social, entre outros, traz a necessidade de algumas reflexões.

Inicialmente, a própria característica dos sujeitos do estudo, refletida em comportamentos de adesão irregular, pode se relacionar ao desconhecimento ou não reconhecimento de abordagens complementares ao tratamento médico. É importante considerar a possibilidade de pouca oferta desses serviços para o público, refletindo aspectos da dimensão programática ${ }^{(8)}$ (papel que as instituições de saúde, educação, entre outras, têm no processo de vulnerabilização de sujeitos e grupos sociais) da vulnerabilidade vivenciada, que pode ser agravada por questões atitudinais da equipe de saúde.

Especificamente em relação às atitudes dos médicos, em um estudo ${ }^{(32)}$, percebeu-se que os exames de carga viral tomam a maior parte do tempo das consultas, e poucas vezes os médicos abordavam aspectos subjetivos dos pacientes. Por outro lado, ao analisarem as percepções dos pacientes, os pesquisadores apontam que o exame se caracterizou como uma maneira de ver a doença, de forma mais clara e concreta, acreditando que só através dele é que os médicos conseguiriam ajudar.

A evolução nos exames e nos medicamentos de controle da AIDS/HIV trouxe avanços inestimáveis para a sobrevida e qualidade de vida dos sujeitos infectados. No entanto, conforme constatado no atual estudo, no qual todos os sujeitos manifestam a contradição entre a percepção de que o tratamento é importante (muitas vezes, vital) para as suas vidas e a não adesão de forma regular a ele, observase a necessidade da ampliação no espectro de cuidado recebido por essa população. Essa ampliação deve se iniciar pela percepção - tanto dos profissionais quanto dos sujeitos que vivem com o HIV - da saúde como uma condição para além dos aspectos biológicos, com o desenvolvimento de 
ações interdisciplinares abordando os múltiplos aspectos biopsicossociais, revertendo-os em melhorias que se somem aos ganhos provenientes do cuidado médico.

Quando questionados sobre as dificuldades na adesão ao tratamento, os entrevistados da presente pesquisa destacaram como limitações para frequentar as consultas médicas (realizadas mensalmente) as questões relacionadas ao trabalho e às suas condições financeiras. Com relação ao trabalho, destacou-se a incompatibilidade de horários deste com o funcionamento do serviço de saúde, o que acarreta a necessidade de faltar ao trabalho para poder ir à consulta médica.

“(...) Não dá pra ficar saindo do serviço direto, assim. Ai o que me atrapalha é na parte do serviço, então..." (E9)

Outro aspecto se refere às condições econômicas precárias vivenciadas, que impedem a ida à consulta médica e, muitas vezes, dificultam a adesão ao uso dos medicamentos. Os entrevistados apontaram a impossibilidade de arcar com os gastos financeiros de transporte para a consulta, algumas vezes, associados a outros gastos decorrentes do tratamento, como aqueles para manter uma boa alimentação.

“(...) Às vezes, você tem dinheiro pra manter sua casa, manter sua comida, porque sua medicação é muito forte e você tem que estar alimentado. Então, você tem que comer uma coisa, assim, não digo melhor, mas você tem que ter uma verdura, uma carne, uma comida normal para tomar a medicação. Então, às vezes, a consulta é no final do mês, você não tem dinheiro, ou você vem a pé ou fica em casa. É muito difícil..." (E8)

A incompatibilidade entre o trabalho e a frequência aos serviços de saúde foi encontrada em outros estudos ${ }^{(11,33,34)}$ direcionados para a compreensão de questões referentes à saúde masculina. Eles trazem a concepção hegemônica de homem como provedor material da casa como um dos motivos que impedem a busca de métodos preventivos e cuidados à saúde. Além disso, é consensual, por parte dos pesquisadores, a necessidade de mudanças nos horários e nas dinâmicas de funcionamento dos serviços de saúde, a fim de contemplar as necessidades dos homens trabalhadores.

No entanto, no presente estudo, além desses fatores, destacou-se o cenário de intensa pauperização e vulnerabilização social entre os homens participantes, o que suscita a reflexão, por parte dos profissionais de saúde, sobre a necessidade do desenvolvimento de ações intersetoriais efetivas, visando garantir o acesso à saúde, que é um direito social básico.

Especificamente em relação às dificuldades no uso da TARV, a maioria dos entrevistados destacou a presença de efeitos colaterais, como vômitos, mal-estar, sonolência, assim como a quantidade e a rotina de uso dos medicamentos.
“(...) Com esse negócio de horário, né... você não pode pegar e esquecer. Tem que ser de manhã, tem que ser no almoço, tem que ser na janta. Almoço, de manhã e janta.. Quer dizer, faz parte; já faz parte da sua vida..." (E3)

Os resultados da presente pesquisa vão ao encontro de pesquisas que discutem os fatores que interferem na boa adesão aos medicamentos, independentemente do gênero. Entre eles, destacam-se: grande quantidade, incompatibilidade com drogas, dificuldade na compreensão das metas da terapia, horários de utilização, sabor e cheiro desagradáveis, esquecimento, desânimo, interrupção para ingerir álcool, falta de confiança no tratamento, orientação insatisfatória, falta de confiança no médico, complexidade do tratamento, alguns precisam ser ingeridos com alimentos e outros em jejum, medo de outras pessoas descobrirem seu estado, dificuldade em dissolver ou engolir ${ }^{11,26,27,29)}$.

As dificuldades encontradas no uso da TARV realçam a decisão da pessoa portadora de HIV em mudar seu ritmo de vida para gerir e aceitar certos efeitos adversos, e suscitam a necessidade de ações de suporte, por parte da equipe de saúde, que tragam contribuições positivas especificas para a realidade de cada sujeito.

No entanto, entrevistados do atual estudo apontaram o esquecimento ou a parada no uso da TARV como uma atitude de descuido ou voluntariamente assumida.

\section{“(...) Queria parar com o tratamento. Não esquentei mais com a medicação, abandonei tudo..." (E8)}

Além disso, destaca-se, nas falas de outros sujeitos, a utilização de bebidas alcoólicas e/ou outras drogas como fatores que impediram, em alguns momentos, a utilização da medicação.

“(...) A maioria dos homens, por beber, tem pavor de médico. E eu mesmo era teimoso, mas bebia todas... Os remédios não faziam efeito... né?" (E9)

O uso de drogas ilícitas e/ou álcool é considerado uma barreira à adesão ao tratamento de HIV, influenciando negativamente todo o processo terapêutico ${ }^{(11,14,21,29)}$. Esse aspecto aponta para a necessidade de intervenções subsidiadas pelo princípio da integralidade no cuidado ao usuário do sistema único de saúde, considerando as especificidades de gênero e articulando ações destinadas à abordagem da dependência química e ao tratamento para o HIV/AIDS

\section{CONSIDERAÇÕES FINAIS}

De uma forma geral, a análise dos significados de viver com o HIV trouxe à tona a necessidade de compreensão desse processo, pois aspectos individuais, que demarcam 
a subjetividade de cada participante, articulam-se, transformam-se e são transformados por fatores construídos na vivência da experiência cultural, social e econômica. Essa complexidade se explicita claramente na identificação da contradição entre a valorização racional da importância do tratamento e as atitudes que caracterizam a adesão irregular a ele.

Os significados de viver com o HIV, para os participantes do estudo, são permeados pela coexistência entre algumas concepções equivocadas, consolidadas no início da epidemia, e a valorização de aspectos que caracterizam o homem como forte e invulnerável. Esses aspectos podem ser compreendidos como um dos fatores que se refletem na forma como os homens aderem ao uso da TARV. Além disso, no presente estudo, o uso de substâncias psicoativas e as condições concretas de vida dos sujeitos, principalmente no que se refere ao âmbito econômico e cultural, podem influenciar nas (im)possibilidades desses homens de cuidarem da sua saúde.

Considerando-se esse cenário, foi possível vislumbrar as manifestações, em suas diferentes dimensões (individual, social e programática), da vulnerabilidade a que estão susceptíveis os homens com o HIV.

O presente estudo, embora tenha encontrado dificuldades para a sua execução, relacionadas à localização dos sujeitos e agendamento das entrevistas (justamente em virtude da adesão irregular ao serviço), apontou aspectos que, embora não possam generalizar, suscitam a reflexão, por parte dos profissionais de saúde, sobre os diferentes aspectos que afetam as (im)possibilidades dos homens de aderirem de forma satisfatória ao uso da TARV.

Nesse sentido, reafirma-se a necessidade do planejamento de intervenções que aproximem os homens dos serviços de saúde e culminem em estratégias estimuladoras, consolidando a valorização de aspectos como o autocuidado e a adoção de medidas preventivas como pertinentes ao universo masculino.

\section{REFERÊNCIAS}

1. Couto MT, Pinheiro TF, Valença O, Machin R, Silva GSN, Gomes R, et al. O homem na atenção primária à saúde: discutindo (in)visibilidade a partir da perspectiva de gênero. Interface Comun Saúde Educ. 2010;14(33):257-70.

2. Gomes R. Os homens e o cuidado com a saúde. In: Gomes R. A saúde do homem em foco. São Paulo: UNESP; 2010. p.27-49.

3. Leite DF, Ferreira IMG, Souza MS, Nunes VS, Castro PR. A influência de um programa de educação na saúde do homem. Mundo Saúde. 2010;34(1):50-6.
4. Marques Junior JS, Gomes R, Nascimento EF. Masculinidade hegemônica, vulnerabilidade e prevenção ao HIV/AIDS. Ciênc Saúde Coletiva. 2012;17(2):511-20.

5. Rebello LEFS, Gomes R, Souza ACB. Homens e a prevenção da AIDS: análise da produção do conhecimento da área da saúde. Interface Comun Saúde Educ. 2011;15(36):67-78.

6. Gomes R, Moreira MCN, Nascimento EF, Rebello LEF, Sousa, Couto MT, et al. Os homens não vêm! Ausência e/ou invisibilidade masculina na atenção primária. Ciênc Saúde Coletiva. 2011;16(Supl):98392.

7. Ministério da Saúde (BR), Secretaria de Atenção a Saúde, Departamento de ações programáticas estratégicas. Política Nacional de Atenção Integral à Saúde do Homem: princípios e diretrizes [acesso em 2011 Ago 8\}. Brasília; 2008. Disponível em: http://dtr2001.saude.gov.br/sas/ PORTARIAS/Port2008/PT-09-CONS.pdf

8. Ayres JRCM, Calazans GJ, Saletti Filho HC, França Junior I. Risco, Vulnerabilidade e práticas de prevenção e promoção da saúde. In: Campos GWS, Minayo MCS, Akerman M, Drumond Junior M, Carvalho YM. Tratado de saúde coletiva. $2^{\mathrm{a}}$ ed. São Paulo: Hucitec; 2009. p.375-417

9. Barros VL, Araújo MAL, Alcântara MNA, Guanabara MAO, Melo SP, Guedes SSS. Fatores que interferem na adesão de gestantes com HIV/AIDS à terapia antiretroviral. Rev Bras Promoç Saúde. 2011;24(4):396403.

10. Nemes MIB. Adesão ao tratamento, acesso e qualidade da assistência em AIDS no Brasil. Rev Assoc Med Bras. 2009;55(2):207-12.

11. Silva ALCN, Waidman MAP, Marcon SS. Adesão e nãoadesão à terapia anti-retroviral: as duas faces de uma mesma vivência. Rev Bras Enferm. 2009;62(2):21320 .

12. Amorim CM, Szapiro AM. Analisando a problemática do risco em casais que vivem em situação de sorodiscordância. Cienc Saude Coletiva. 2008;13(6):1859-68.

13. Teixeira MG, Silva GA. A Representação do portador do vírus da imunodeficiência humana sobre o tratamento com os anti-retrovirais. Rev Esc Enferm USP. 2008;42(2):729-36.

14. Blatt CR, Citadin CB, Souza FG, Mello RS, Galato D. Avaliação da adesão aos anti-retrovirais em um 
município no Sul do Brasil. Rev Soc Bras Med Trop. 2009;42(2):131-6.

15. Costa DAM, Zago MMF, Medeiros M. Experiência da adesão ao tratamento entre mulheres com Vírus da Imunodeficiência Humana/ Síndrome da Imunodeficiência Adquirida. Acta Paul Enferm. 2009;22(5):631-7.

16. Bonolo PF, Gomes RR, Guimarães MD. Adesão à terapia anti-retroviral (HIV/AIDS): fatores associados e medidas de adesão. Epidemiol Serv Saúde. 2007;16(4):261-78.

17. Pérsico BFG, Figueiredo MAC. Grupos de adesão como fonte de recursos no convívio com HIV/AIDS. Rev SPAGESP. 2008;9(1):21-8.

18. Ministério da Saúde (BR), Secretaria de Vigilância em Saúde, Programa Nacional de DST e AIDS. Manual de adesão ao tratamento para pessoas vivendo com HIV e AIDS [acesso em 2011 Ago 8]. Brasília; 2008. Disponível em: http://bvsms.saude.gov.br/bvs/ publicacoes/manual_adesao_tratamento_hiv.pdf

19. Polejack L, Seidl EMF. Monitoramento e avaliação da adesão ao tratamento antirretroviral para HIV/ aids: desafios e possibilidades. Cien Saude Colet. 2010;15(1):1201-8.

20. Minayo MCS. O desafio do Conhecimento. $10^{\mathrm{a}}$ ed. São Paulo: Hucitec; 2010.

21. Flick U. Introdução à pesquisa qualitativa. Porto Alegre: Artmed; 2009.

22. Gomes R. Análise e interpretação de dados de pesquisa qualitativa. In: Minayo MCS, organizador. Pesquisa social: teoria, método e criatividade. Rio de Janeiro: Vozes; 2008. p.79-108.

23. Reis RK, Gir E. Vulnerabilidade ao HIV / AIDS e a prevenção da transmissão sexual entre casais sorodiscordantes. Rev Esc Enferm USP. 2009;43(3):662-9.

24. Souza VS, Czeresnia D. Demandas e expectativas de usuários de centro de testagem e aconselhamento antiHIV. Rev Saúde Pública. 2010;44(3):441-7.

25. Gomes R. Sexualidade masculina, gênero e saúde. Rio de Janeiro: Fiocruz; 2008.
26. Meirelles BHS, Silva DMGV, Vieira FMA, Souza SS, Coelho IZ, Batista R. Percepções da qualidade de vida de pessoas com HIV/AIDS. Rev Rene. 2010;11(3):6876

27. Seben G, Gauer GJC, Giovelli GRM, Vieira RG. Adultos jovens portadores de HIV: análise dos processos subjetivos no enfrentamento da doença. Psic Rev Psicol Vetor Ed. 2008;9(1):63-72.

28. Vidal ECF, Braga VAB, Silva MJ, Pinheiro AKB. Políticas Públicas para pessoas com HIV: discutindo direitos sexuais e reprodutivos. Rev RENE. 2009;10(2):166-74.

29. Melchior R, Nemes MIB, Alencar TMD, Buchalla CM. Desafios da adesão ao tratamento de pessoas vivendo com HIV/AIDS no Brasil. Rev Saúde Pública. 2007;41(2):87-93.

30. Carvalho FT, Morais NA, Koller SH, Piccinini CA. Fatores de proteção relacionados à promoção de resiliência em pessoas que vivem com HIV/AIDS. Cad Saúde Pública. 2007; 23(9):2023-33.

31. Padoin SMM, Machiesqui SR, Paula CC, Tronco CS, De Marchi MC. Cotidiano terapêutico de adultos portadores da Síndrome de Imunodeficiência Adquirida. Rev Enferm UERJ. 2010;18(3):389-93.

32. Guzmán JLD, Iriart JAB. Revelando o vírus, ocultando pessoas: exames de monitoramento (CD4 e CVP) e relação médico-paciente no contexto da AIDS. Cad Saúde Pública. 2009;25(5):1132-40.

33. Schraiber LB, Figueiredo WS, Gomes R, Couto MT, Pinheiro TF, Machin R, et al. Necessidades de saúde e masculinidades: atenção primária no cuidado aos homens. Cad Saúde Pública. 2010;26(5):961-70.

34. Gomes R, Nascimento EF, Araujo FC. Por que os homens buscam menos os serviços de saúde do que as mulheres? As explicações de homens com baixa escolaridade e homens com ensino superior. Cad Saúde Pública. 2007;23(3):565-74.

\section{Endereço para correspondência: \\ Daniela Tavares Gontijo \\ Universidade Federal de Pernambuco \\ Departamento de Terapia Ocupacional \\ Av. Prof. Moraes Rego, s/n, Cidade Universitária \\ CEP 50670-901 - Recife - PE - Brasil \\ Email: danielatgontijo@gmail.com}

